\title{
Schizophrenic psychosis associated with aqueduct stenosis in adults
}

\author{
JKA ROBERTS*, MR TRIMBLE, M ROBERTSON \\ From the Department of Psychological Medicine, National Hospital for Nervous Diseases, London
}

SUMMARY The case histories of five adult patients with hydrocephalus and aqueduct stenosis are presented. All the cases were associated with prominent psychotic symptoms (delusions, hallucinations or thought disorder). In the three cases where operative intervention was carried out the diagnosis was made in adult life. Using the Present State Examination all five cases were classified as having schizophrenic psychosis. The possible reasons for this association are discussed.

Non-tumoral stenosis of the Sylvian aqueduct is a disease that usually presents in infancy and childhood $^{1-4}$ but it is well documented as being diagnosed in older patients (over 17 years of age) and the authors have traced 160 such cases in the literature..$^{1-35-25}$ These adult patients commonly present with neurological symptoms or signs and in all the cases identified there was evidence of prominent psychotic symptoms (delusions, hallucinations or thought disorder) in only two. Elvidge ${ }^{12}$ described a 46-year-old woman who showed "psychotic behaviour" and subsequently required chronic institutionalisation, and Little et $a l^{23}$ described a 24-year-old woman who showed the features of "endogenous depression". In both cases these symptoms were part of the presenting picture leading to the diagnosis of aqueduct stenosis. Others have described "unusual" behaviour, ${ }^{13}{ }^{15}$ alterations of mood $^{3781013}$ and personality change. ${ }^{111315}$ Globus and Bergman $^{2}$ described a 49-year-old woman who experienced auditory hallucinations of "bells and whistles" but no other psychotic symptomatology.

This paper presents further evidence of an association between psychosis and aqueduct stenosis in five adults and their case histories are presented with a discussion of the possible reasons for this association.

\footnotetext{
*Present Address: Royal Ottawa Hospital, 1145 Carling Avenue, Ottawa, Ontario, Canada K1Z 7K4.
}

Address for reprint requests: Dr MR Trimble, National Hospital for Nervous Diseases, Queen Sq, London WC1J 3BG, UK.

Received 14 November 1981 and in revised form 4 March 1983. Accepted 14 May 1983.

\section{Case reports}

Case 1 Miss $\mathrm{BC}$ became ill at the age of 15 years when her academic performance at school began to deteriorate and she began to withdraw from social relationships, whereas previously she had been outward going and cheerful. Her change in behaviour was first noted at the age of 21 when she left her job as a librarian, following a clash of $\frac{\tilde{D}}{\mathrm{D}}$ personalities with her employer. She then began to havee considerable difficulty gaining consistent employment, her behaviour being noted to be eccentric. When employed shen had a tendency to appear bored, laugh to herself and neg-o lect her work. Concerned at her behaviour her relatives took her to hospital for assessment and at that time she was noted to have a strange dysplastic facial appearance and a history of a late menarche at the age of 19 years. Because of these findings she was admitted for assessment. On admission her thinking was noted to be disturbed, answering questions tangentially, as well as exhibiting strange muttering and giggling behaviour. Her memory was poor and she had patchy recall for a simple story told three minutes previously and a defective recall for geometric designs. She also had difficulty in naming towns and identifying colours. Her physical appearance was unkempt and her feet and clothes were dirty. Her head was enlarged with a circumference about the 95 th percentile for her age. She was slightly myopic in her left eye but no other abnormality was found on examination. An electroencephalogram (EEG) was normal. A computed tomography (CT) head scan showed hydrocephalus involving the lateral and third cerebral ventricles only and was reported as showing the typical picture of hydrocephalus in association with stenosis of the Sylvian aqueduct. There was a short-lived improvement in her mental state following the insertion of a ventriculo-peritoneal shunt into her left lateral ventricle, but her behaviour rapidly deteriorated. She began to exhibit pressure of speaking and became aggressive. On post-operative reassessment a few weeks later she laughed frequently and inappropriately, answered questions off the point and was disoriented for time. Her finer feelings, 892 
motivation, persistence and awareness were noted to have deteriorated. A repeat CT head scan showed there had been minimal reduction in her lateral ventricles compared to their pre-operative size and so her medium pressure Holter valve was replaced with a low pressure valve, but with no improvement in her mental state or the size of her cerebral ventricles. She was then referred for psychiatric assessment at the National Hospital for Nervous Diseases. Her personal history revealed that she was the third of five siblings. Both her parents were alive and well and she was living with them. The only family history of note was an aunt with probable schizophrenia and a cousin who had had an unspecified psychiatric illness. The patient's birth and early development had been normal. She had had no sexual experience and few boyfriends. There was no previous medical or psychiatric history of significance. On admission she was noted to be somewhat unkempt in appearance, suspicious and exhibited a flat affect. There was pressure of talk but no elation of mood and her speech tended to be circumstantial. Her social behaviour had clearly deteriorated and she was seen to swear frequently at her mother in public for trivial reasons. Hypergraphia was present. She described an episode when she had been walking down the high street and had heard a voice say to her "this is my normal voice". She believed that this had been caused by her local parish priest and that he was able to throw his voice. She also felt that her departmental manager at work was a ventriloquist capable of throwing his voice and imitating people, and that one of the secretaries was a medium who could make her hear things. She had a persistent delusion that there was a three inch part of a sewing machine inside her vagina. A subsequent examination failed to confirm this. She was right handed. On neurological examination she was found to exhibit a convergent retractory nystagmus. The saccadic amplitude, peak velocity and smooth pursuit velocity of her eye movements, were within normal limits. A standard EEG showed marked asymmetry with a large amplitude of alpha activity on the left side which was probably the result of her previous neurosurgery. Her intermittent aggression, apathy and social withdrawal were mildly improved with pimozide, but remained a problem and disrupted her home situation to a degree where it was necessary to make arrangements for hostel care. Her progress was followed for several months but her delusion remained fixed.

Case 2 Miss BG was a 17-year-old insurance clerk who first became mentally ill two years earlier, while at school. She began to develop ideas of persecution while preparing for her school examinations. The ideas settled without treatment but were soon followed by headaches, nausea, vomiting, diarrhoea, paraesthesiae in the extremities of her limbs and blurring of vision. Her ideas of persecution returned and she began to express the belief that the other girls at the insurance company where she was now working were talking about her behind her back and making remarks such as "she is one of them" and "look at her she has got herself pregnant". She felt strangers in the street were passing remarks about her, her sleep became disturbed and on one occasion she ran into her house to tell her parents that the cars in the street were hooting and flashing their lights at her and that the family must leave and move to another area. She then developed the idea that there were special messages for her on television and in magazines. Because of her behaviour her relatives took her to the Maudsley Hospital for assessment. Her personal history revealed that she was the second born of unexpected twins and was a forceps delivery. Her parents were alive and well and there was no family history of neuropsychiatric illness. Her early life was normal except for a tendency to be quiet, anxious and self-absorbed. She had few close friends and performed at an academically average level at school. Menarche was at the age of 11 years and she had had no sexual experience. There was no other relevant previous medical or psychiatric history. On examination she was found to be clean, tidy and neatly dressed. She was slow to answer questions and appeared tense and bewildered. Her voice was low and monotonous and she exhibited a flat affect. There was no pressure of speech and her cognitive functions were normal though she had no insight into her illness. Physical examination showed her to have a large head and mild bilateral papilloedema which was subsequently confirmed by fluoroscein angiography. A skull radiograph showed a thin central vault with widespread digital markings. The sutures were prominent and her pituitary sella was deepened, the dorsum sella being short and the posterior fossa shallow. The picture was felt to be that of longstanding hydrocephalus probably due to aqueduct stenosis. Carotid angiography confirmed the hydrocephalus and a left vertebral angiogram showed the cerebellar hemispheres to be small and the fourth ventricle to be in its normal position. The cerebellar tonsils had herniated through the foramen magnum. Two EEGs showed an excess of both slow and sharp wave activity over the right posterior temporal region. On psychological testing she had a Wechsler Adult Intelligence Scale (WAIS) verbal intelligence quotient (IQ) of 93 and a performance IQ of 83. After consultation with the neurosurgeon it was felt that surgical intervention was not indicated at this stage. Her behaviour on the ward showed a marked periodicity with episodes of excitement, fear and delusions of reference, lasting two to three days. These episodes were separated by periods in which she exhibited apathy, social withdrawal and affective incongruity, usually lasting four to five days. During the latter episodes she would appear anxious and miserable with cold extremities and her performance on digit symbol and verbal fluency tests supported the clinical impression of a slowing in her cognitive processes. Her eye movement speed was also noted to be reduced at these times. Her behaviour gradually settled on no medication and she was discharged home. She was readmitted six months later with headaches, nausea and vomiting. CT with contrast was carried out which confirmed that her intracranial pressure was raised and that she had aqueduct stenosis and hydrocephalus. A shunt was not inserted. Investigations included plasma cortisols which were normal and showed a normal diurnal rhythm. An EEG showed a moderate right temporo-occipital non-epileptiform abnormality. She was discharged home and over the next two years she became progressively more apathetic and withdrawn. Her menstrual periods became irregular and on one occasion she did not menstruate for 11 months. She was reassessed two years later and was noted again to have a flat affect. She 
would sit quietly and unoccupied for hours at a time. Though abnormal experiences were denied she appeared at times to be listening to auditory hallucinations. She was poor at calculations and any other tests requiring sustained attention but her cognitive functions appeared otherwise normal. Physical examination revealed a mild papilloedema was still present and she had symmetrically brisk tendon jerks with ankle clonus but flexor plantar responses. Her plasma cortisols were mildly elevated being $695 \mu \mathrm{mol} / 1$ (normal range $110-530 \mu \mathrm{mol} / \mathrm{l}$ ) and 233 $\mu \mathrm{mol} / \mathrm{l}$ (normal range under $110 \mu \mathrm{mol} / \mathrm{l}$ ) in the mornings and evenings respectively. An adrenocorticotrophic (ACTH; hormone stimulation test was normal. A CT head scan confirmed hydrocephalus secondary to aqueduct stenosis. She was started on pimozide and there was a mild reduction in her social withdrawal. She was discharged to a hostel.

Case 3 Mr GK, a 23-year-old maintenance apprentice, first became ill at the age of thirteen when he began to develop headaches with vomiting. These episodes were initially diagnosed as migraine. Over the next two years his intellect began to deteriorate, his personality changed, his weight increased and he became intermittently incontinent of urine at night. Shortly after an accident when he fell and fractured his pelvis, he was noted to have periods of somnolence associated with incontinence of urine and unsteadiness of gait. He became unconcerned about his personal hygiene. He was admitted to hospital for investigation and found at that time to be a physically underdeveloped young man with poor development of his secondary sexual characteristics, and ataxia of gait. A Myodil ventriculogram showed a stricture of the Sylvian aqueduct and an anterior IIIrd ventriculostomy was carried out with subsequent clinical improvement to a degree where he was able to return to work. He remained well for the next three years until a recurrence of his headaches and vomiting required a revision of his ventriculocisternostomy. Neurological examination during this admission to hospital revealed an impairment of ocular convergence. Following the operation he became more aggressive, erratic in his behaviour and changeable in his mood. Six months prior to his admission to the Maudsley Hospital he became secretive, developed an obsessive interest in religion and told his father that he had been "chosen". He also developed a delusion that a local girl was in love with him, though in fact he had had little contact with her. His work performance deteriorated, his concentration became poor and he became restless to a degree where it was necessary to admit him. His previous history revealed that he was the second eldest of five siblings. Both his parents were alive and well and there was no family history of neuropsychiatric illness. He was born prematurely, $2 \mathrm{~kg}$ in weight, but his early development was otherwise normal. He was bright academically but had few friends, was shy and tended to show little affection for others. Onset of puberty was at the age of 17 years and his first sexual experience was at the age of twenty-two. His mental state showed him to be overactive with pressure of speech and flight of ideas but no elation of mood. He had the delusional belief that he possessed special powers which enabled him to understand people. No other psychotic phenomena were elicited except for his belief that he was "chosen" by God. His affect was flat and his cognitive functions appeared to be intact. On physical examination he was noted to have a markedly enlarged head which carried the stigmata of his previous craniotomies. Psychological testing revealed a WAIS verbal IQ of 116 and a performance IQ of 103. No memory impairment was found. A standard EEG showed minimal abnormalities consistent with his previous craniotomies. His thought disorder and delusions responded well to thioridazine but he remained socially withdrawn. His parents were unable to cope with his behaviour and so he was subsequently discharged into hostel care.

Case 4 Mrs DE was a 50-year-old secretary who was first seen by a psychiatrist at the age of 48 . At that time she was complaining of strange short-lived experiences during which she believed she was receiving threatening telephone calls from members of the royal family. These "dream-like" experiences had been occurring for several weeks, mainly at night. She gradually became socially withdrawn and began to complain of episodic dizziness, difficulty with walking, a feeling of coldness, poor concentration, loss of energy, indecisiveness and depression of mood. When examined by a physician no abnormality was found except that her secondary sexual characteristics, such as her pubic hair were poorly developed. Routine blood tests including plasma cortisols were normal. A skull radiograph showed mild osteoporosis of the dorsum sella. A diagnosis of depression was made and there was some clinical improvement on treatment with an antidepressant. One year later her experiences recurred and she was now also complaining of tremor of her hands. On examination she was noted to have a Parkinsonian gait with a fine tremor of her tongue and her hands. There were hyperreflexic tendon jerks in both upper limbs but normal reflexes, with some muscle weakness, in both lower limbs. Plantar responses were flexor. A skull radiograph showed a mild asymmetry of the pituitary fossa. Psychological testing revealed a WAIS verbal IQ of 122 and a performance IQ of 99. There was a wide variation of scores across the sub-tests and she performed poorly on timed tests. Her performance on memory and new learning tasks was normal. She was transfered to the National Hospital for further investigations. Personal details were limited though they indicated that she was a lady of high intelligence premorbidly, who had been working as a secretary at a school up until the onset of her illness. She had had amenorrhoea ever since a miscarriage at the age of 24 . A CT head scan showed that her lateral and third cerebral ventricles were grossly dilated with a normal fourth ventricle. A metrizamide ventriculagram showed hydrocephalus with aqueduct stenosis and no evidence of a tumour. A ventriculo-atrial shunt was inserted and she made an uneventful recovery with a postoperative CT head scan showing minimal reduction in ventricular size. She returned home, her physical and mental state improving, until several months later when she developed paranoid ideas, an unsteady gait and urgency of micturition. She claimed that she knew whatever people were thinking and that her actions were directly influenced by other peoples' thoughts. She was readmitted to the National Hospital and mental state evaluation revealed pressure of speech but 
without elation of mood or thought disorder. She was hypergraphic. Her cognitive functions were normal. Her shunt was working normally and there were no focal neurological signs on examination. A CT head scan showed her cerebral ventricles were now normal in size with the shunt entering the right lateral cerebral ventricle. A standard EEG was normal and she refused psychological testing. She was subsequently discharged home on perphenazine.

Case 5 Mrs RD was a 49-year-old lady who had in the past been an unskilled factory worker, but most of her last ten years had been spent in psychiatric institutions. She had been born by breech delivery following which she developed hydrocephalus and muscle spasticity of her limbs. Her subsequent motor development was delayed and she went to a special school for the physically handicapped, until the age of eleven when she had to be transferred to a children's home as her father had died at a local psychiatric hospital. At the age of 27 years she had a brief psychiatric admission for depression and two years later began to have grand mal convulsions. These seizures were usually not preceded by an aura, though occasionally she experienced a transient feeling of pressure on her head and "muddled" thinking beforehand. An EEG showed generalised high amplitude theta activity mixed with paroxysmal slow and sharp wave complexes. There were no focal abnormalities. She was subsequently treated with phenobarbitone. At the age of 36 years she developed auditory hallucinations and paranoid delusions. Her delusions remained fixed and systematised. They involved her believing that there were four people talking about her in an aggressive and insulting way, sometimes referring to her in the third person. She subsequently had frequent admissions during exacerbations of her psychosis and on one occasion was examined by a neurologist and found to have a skull circumference of $63 \mathrm{~cm}$, paralysis of ocular convergence, slurred speech, minimal ataxia of the left arm, and moderate spasticity of both legs with bilateral extensor plantar responses. No spinal malformations were found and her visual fields and fundi were normal. Her serum anticonvulsant levels were consistently within the therapeutic range. A skull radiograph showed evidence of long-standing hydrocephalus. An EEG showed no changes from her previous EEG. Psychological testing revealed a WAIS verbal IQ of 90 and a performance IQ of 70 . There was noted to be a great variation in her performance on the WAIS subtests. She was able to read and write normally. Memory impairement was marked and she was unable to reproduce a short story one hour after hearing it and could not correctly reverse more than three digits. Her personal history revealed that both the parents were dead and apart from her father, who had suffered from marked ideas of reference and had made two suicide attempts, there was no other family history of neuropsychiatric illness. She was the fifth of seven siblings. Menarche was at the age of 16 years and her first sexual experience was in her twenties. She had had only two transient sexual relationships, each resulting in the birth of a son. She was described as being emotionally unstable in her childhood but there was little information about her premorbid personality. On recent examination she was noted to talk normally and appropriately though she exhibited some stereotyped speech and had a flat affect. Her delusional system remained intact. Her usual behaviour involved walking aimlessly along the corridors of the hospital. She required supervision to ensure she bathed and looked after her appearance. Her fits continued intermittently. She was reassessed by a neurosurgeon at this time and it was felt that as she was not incontinent and there had been little deterioration in her gait, there was no indication for surgical intervention. A CT head scan showed massive enlargement of the lateral and third ventricles with normal cerebral sulci, the appearance being strongly suggestive of hydrocephalus and aqueduct stenosis.

\section{Discussion}

The Present State Examination was completed on all cases though this was retrospectively done (using the extremely detailed Maudsley notes) in cases 2 and 3 , these being the only two cases not examined by at least one of the authors. The data were analysed by computer using the Catego program and they were all classified as having a schizophrenic psychosis $(\mathrm{S}+)$. Cases 1,4 (passivity experiences), and 5 (auditory hallucinations referring to the patient in the third person) were each subclassified as nuclear schizophrenia (NS+) owing to the presence of these first rank Schneiderian symptoms. Cases 2 and 3 were each subclassified as schizophrenia without first rank symptoms (DS+).

That hydrocephalus has been present since infancy seems likely in cases $1,2,3$ and 5 , in view of the head enlargement that was found in these patients. In addition birth trauma of possible aetiological significance, was clearly present in cases 2,3 and 5. Operative intervention preceded the onset of psychotic symptoms in case 3 but succeeded them in cases 1 and 4 . There was no evidence that operative intervention had any influence on these symptoms despite a definite postoperative reduction in cerebral ventricular size in case 4 . On the basis of this limited series of cases there is no evidence that the development of the schizophrenic psychoses was either related to or influenced by, operative intervention. However it seems likely that such intervention was relatively late in the course of the disorder in these cases.

There is insufficient information to assess the progress in case 4 but in the other cases the illness clearly resulted in a degree of handicap. In cases 1,2 and 3 the patients were unable to continue living at home and required hostel care, and case 5 had been chronically institutionalised for many years. Positive psychotic symptoms (delusions and hallucinations) were not the only handicaps in these patients and there was also a deterioration in social behaviour with social withdrawal (cases 1, 2, 3 and 5), aggres- 
sion (case 1), and a loss of concern for personal care (cases 1 and 5).

In view of the relative rarity with which aqueduct stenosis is diagnosed in adults and the relatively short time during which these cases were collected, a coincidental association between the psychoses and aqueduct stenosis does not seem to explain adequately these findings. In addition, only in case 1 is there any evidence for a genetic predisposition to schizophrenia. It seems probable that the hydrocephalus, or the factors predisposing to the development of the hydrocephalus, contributed in some way to the development of the psychosis. Many organic diseases of the central nervous system, particularly those involving the temporal lobe and the diencephalic regions of the brain ${ }^{27}$ have been shown to be associated with schizophrenia-like psychoses that are virtually indistinguishable from the "primary" schizophrenias. To what extent the deterioration in social behaviour can be regarded as a "psychiatric" or a "neurological" phenomenon it is not possible to say. However such a clinical picture and course has been described in schizophrenic patients with enlarged cerebral ventricles but no recognised neurological disorder. ${ }^{28}$ In addition, since submission of this paper, Reveley and Reveley ${ }^{29}$ have published in this Journal, case histories of three patients from a series of schizophrenics being evaluated with CT scans who had hydrocephalus secondary to aqueduct stenosis.

There is evidence that the enlarged third ventricle pressing on the diencephalon is responsible for the endocrine disturbances reported in the literature on aqueduct stenosis. ${ }^{121-23}$ Delayed puberty was present in cases 1, 3 and 5, and prolonged amenorrhoea and poorly developed secondary sexual features in case 4 , thus providing evidence compatible with a longstanding diencephalic dysfunction in these patients.

Pressure of speech was noticed in cases 1, 3 and 4 and transient manic reactions have been noted in hypothalamic dysfunction. ${ }^{39}$ The periodicity of symptomatology in case 2 has been described in association with aqueduct stenosis by other authors, ${ }^{79}$ and in some cases episodic autonomic changes and psychomotor slowing have been found. ${ }^{2025}$ This periodicity has been ascribed to the aqueduct acting intermittently in a valve-like way which can produce transient episodes of raised pressure in the third ventricle and affect diencephalic function..$^{20}$ A similar periodicity in disturbed behaviour has been described in association with brain stem dysfunction..$^{30}$

Evidence for impaired function of the upper brain stem is provided by the presence of disturbance of eye movements with a convergent retractory nys- tagmus in case 1 and paralysis of gaze convergence in cases 3 and 5. These findings suggest impaired function of the mesencephalon though they are not pathognomonic. ${ }^{31}$ Disturbance of conjugate eye movements were only described in six of the 260 cases of non-tumoral aqueduct stenosis diagnosed in adults, found in the literature by the authors. The findings of this rare occurrence in three of these five cases may indicate the importance of dysfunction in the mesencephalic area of the brain in the aetiology of the psychotic symptoms. In this context it may be relevant that postmortem examination of the brains of schizophrenic patients have repeatedly demonstrated lesions in the mesencephalic/diencephalic region, ${ }^{32-34}$ and other authors have described the development of psychotic symptoms in association with lesions in this area. ${ }^{30} 35$

Some series ${ }^{12123}$ have shown a tendency for patients with aqueduct stenosis to develop temporal lobe epilepsy, which is particularly associated with the development of schizophrenia-like psychosis. ${ }^{27}$ However only case 2 had an EEG consistent with temporal lobe dysfunction and no clinical evidence of temporal lobe epilepsy. Hypergraphia was found in cases 1 and 4 and has been noted to be found in association with temporal lobe epilepsy ${ }^{3637}$ and schizophrenia. ${ }^{38}$ Case 5 appears to have a secondary generalised epilepsy with a diffusely abnormal EEG.

However, brain stem and temporal lobe dysfunction are not mutually exclusive events in aqueduct stenosis and the herniating temporal lobes can act to compress the upper brain stem ${ }^{20}{ }^{39}$ while themselves being subject to distortion as well, thus suggesting that aqueduct stenosis can theoretically be caused by hydrocephalus. If this is true it is possible that both the stenosis and the psychosis are a consequence of the hydrocephalus.

Finally it may be significant that longstanding hydrocephalus can interfere with the development of the cerebellum and cause pressure on and herniation of the cerebellum through the foramen magnum. Though this was most prominent in case 2 it is reasonable to expect similar, if less pronounced, consequences in the other cases. Necropsy ${ }^{41}$ and CT head scan ${ }^{42-44}$ studies of psychotic patients have provided evidence of a subgroup with cerebellar damage. Heath et $\mathrm{l}^{43}$ have proposed that cerebellar dysfunction has an aetiological role in the psychoses. Their theory is based on the results of animal studies linking the cerebellum functionally with the hippocampus and septal regions, but it is controversial and there are findings which contradict the association between psychosis and cerebellar damage. 4546

In conclusion, the evidence suggests that dysfunction in subcortical structures, notably the mesencephalic/diencephalic regions of the brain, 
may play an important role in the aetiology of the schizophrenic psychoses that are found in association with aqueduct stenosis, and it is possible that intrinsic brain stem pathology is responsible for aqueduct stenosis and also for the associated psychosis. The authors also suggest that aqueduct stenosis diagnosed in adults carries with it a significant risk of the development of schizophrenic psychosis.

The authors thank Dr D Bennett, Mr C Polkey and Dr D Smedberg, for their permission to report cases 2,3 and 5 , respectively.

\section{References}

${ }^{1}$ Nag TK, Falconer MA. Non-tumoral stenosis of the aqueduct in adults. $\mathrm{Br} \mathrm{Med} J$ 1966;2:1168-70.

${ }^{2}$ Globus JH, Bergman P. Atresia and stenosis of the Aqueduct of Sylvius. J Neuropath Exp Neurol 1946;5:342-63.

${ }^{3}$ Wilkinson HA, LeMay M, Drew JH. Adult aqueductal stenosis. Arch Neurol 1966;15:643-8.

${ }^{4}$ Ford FR. Diseases of the Nervous System in Infancy, Childhood and Adolescence. Illinois: Charles C. Thomas 1960;223.

5 Friedman G. Die nicht durcht Tumor bedingte Aquäduktstenose und ihr Nachweis im Röntgenübersichtsbild. Der Radiologie 1964;4:190-4.

${ }^{6}$ Lavender JP, Du Boulay GH. Aqueduct Stenosis and cystic expansion of the suprapineal recess. Clin Radiol 1965;16(4):330-3.

${ }^{7}$ Beckett RS, Netsky MG, Zimmerman HM. Developmental stenosis of the aqueduct of Sylvius. Am J Pathol 1950;26:755-88.

${ }^{8}$ Orton ST. A clinical and pathological study of two cases of obstruction of the aqueduct of Sylvius. Bull Neurol Inst, New York 1932;1:72-96.

9 Pennybacker J. Stenosis of the aqueduct of Sylvius. Proc $R$ Soc Med 1940;33:507-12.

${ }^{10}$ Drachman DA, Richardson EP. Aqueductal narrowing, congenital and acquired. Arch Neurol 1961;5:552-9.

$"$ Turnbull IM, Drake CG. Membranous occlusion of the aqueduct of Sylvius. J Neurosurg 1966;24:24-33.

${ }^{12}$ Elvidge AR. Treatment of obstructive lesions of the aqueduct of Sylvius and the fourth ventricle by interventriculostomy. J Neurosurg 1966;24:11-23.

${ }^{13}$ Petit-Dutaillis D, Thiébaut Fr, Berdet H, Barbizet J. Les hydrocéphalies par sténose intrinsèque de l'aqueduc de Sylvius. Sem Hôp Paris 1957;27(5):201-13.

${ }^{14}$ Busch E. Psychical symptoms in neurosurgical disease. Acta Psychiat Neurol 1940;15:257-90.

${ }^{15}$ Petit-Dutaillis D, Thiébaut Fr, Berdet H, Barbizet J. A propos des sténoses de l'aqueduc de Sylvius d'origine non tumoral de l'adolescent et de l'adulte. Rev Neurol (Paris) 1950;82:417-21.

${ }^{16}$ Leckey RG, Morley TP. Septum of the aqueduct of Sylvius: A developmental anomaly, Can J Surg 1959;2:200-3.
${ }^{17}$ Russell DS. Observations on the Pathology of Hydrocephalus. London: HMSO, MRC Special Report Series No. 265 1949,10-50.

${ }^{18}$ McHugh PR. Occult Hydrocephalus. $Q \quad J$ Med 1964;33:297-308.

19 Spiller WG. Two cases of partial internal hydrocephalus from closure of the interventricular passages. $A m ~ J$ Med Sci 1902;124:44-55.

${ }^{20}$ McMillan JJ, Williams B. Aqueduct Stenosis. J Neurol Neurosurg Psychiatry 1977;40:521-32.

${ }^{21}$ Harrison MJG, Robert CM, Uttley D. Benign aqueduct stenosis in adults. J Neurol Neurosurg Psychiatry 1974;37:1322-8.

22 Paine KWE, McKissock.W. Aqueduct stenosis: clinical aspects and results of treatment by ventriculocisternostomy (Torkildsen's operation). 1955;12:127-45.

${ }^{23}$ Little JR, Houser OW, MacCarty CS. Clinical manifestations of aqueductal stenosis in adults. $J$ Neurosurg 1957;43:546-52.

${ }^{24}$ Shelden WD, Parker HL, Kernohan JW. Occlusion of the Aqueduct of Sylvius. Arch Neurol Psychiat 1930;23:1183-1202.

${ }^{25}$ Parker HL, Kernohan JW. Stenosis of the Aqueduct of Sylvius. Arch Neurol Psychiat 1933;29:538-60.

${ }^{26}$ Wing JK, Cooper JE, Sartorius N. The measurement and classification of psychiatric symptoms. An instruction manual for the PSE and Catego program. London: Camb Univ Press 1974.

${ }^{27}$ Davison K, Bagley CR. Schizophrenia-like psychoses associated with organic disorders of the central nervous system. A review of the literature. In: Herrington $\mathrm{RN}$, ed. Current problems in Neuropsychiatry: Schizophrenia, Epilepsy and the Temporal Lobe. $\mathrm{Br} \mathrm{J}$ Psychiat Special Pub No. 4 1969;113-84.

${ }^{28}$ Andreasen NC, Olsen SA, Dennert JW, Smith MR. Ventricular enlargement in schizophrenia: Relationship to positive and negative symptoms. Arch Gen Psychiat 1982;139:297-302.

${ }^{29}$ Reveley AM, Reveley, MA. Aqueduct Stenosis and Schizophrenia. J Neurol Neurosurg Psychiatry 1983;46:18-22.

${ }^{30}$ Oyewumi LK, Lapierre YD. Efficacy of lithium in treating mood disorder occurring after brain stem injury. Am J Psychiat 1981;138:110-113.

${ }^{31}$ Smith BH. Differential diagnosis: Neurology. New York: Arco Publishing Inc 1979.

${ }^{32}$ Nieto D, Escobar A. Major psychoses. In: Minckler J, ed. Pathology of the Nervous System Vol 3. New York: McGraw-Hill 1972;2654-65.

${ }^{33}$ Fishman M. The brain stem in psychosis. Br J Psychiat 1975;126:414-22.

${ }^{34}$ Stevens JR. Neuropathology of schizophrenia. Arch Gen Psychiat 1982;31:1131-9.

${ }^{35}$ Trimble MR, Cummings JL. Neuropsychiatric disturbances following brain stem lesions. Br J Psychiatry 1981;138:56-9.

${ }^{36}$ Waxman SG, Geschwind N. Hypergraphia in temporal lobe epilepsy. Neurology (Minneap) 1974;24:629-37.

${ }^{37}$ Waxman SG, Geschwind N. The interictal behavior syndrome of temporal lobe epilepsy. Arch Gen Psychiat 1975;32:1580-6.

${ }^{38}$ Cairns $\mathbf{H}$. Disturbances of consciousness with lesions of 
the brain stem and diencephalon. Brain 1952;75:109-46.

${ }^{38}$ Critchley M. Aphasiology. London: Edward Arnold 1970;355-8.

${ }^{39}$ Jakubowski J, Jefferson A. Axial enlargement of the 3rd ventricle, and displacement of the brain-stem in benign aqueduct stenosis. $J$ Neurol Neurosurg Psychiatry 1975;35:114-23.

${ }^{40}$ Lishman WA. Organic Psychiatry. London: Blackwell Scientific Publications 1978;280-3.

${ }^{41}$ Weinberger DR, Kleinman JE, Luchins DJ, Bigelow LB, Wyatt RJ. Cerebellar pathology in schizophrenia: a controlled post mortem study. Am J Psychiatry 1980;137:359-61.

${ }^{42}$ Heath RG, Franklin DE, Shraberg D. Gross pathology of the cerebellum in patients diagnosed and treated as functional psychiatric disorders. J Nerv Ment Dis 1979;167:585-92.

${ }^{43}$ Heath RG, Franklin DE, Walker CF, Keating JW. Cerebellar vermal atrophy in psychiatric patients. Biol Psychiat 1982;17:569-83.

44 Lippman S, Manshadi M, Baldwin H, Drasin G, Rice J, Alrajeh S. Cerebellar vermis dimensions of Computerised Tomographic Scans of schizophrenic and bipolar patients. Am J Psychiatry 1982;139:667-8.

${ }^{45}$ Nasrallah HA, Jacoby CG, McCalley-Whitters M. Cerebellar atrophy in schizophrenia and mania. Lancet 1981;1:1102.

${ }^{46}$ Coffman JA, Mefferd J, Golden CJ, Bloch S, Graber B. Cerebellar atrophy in schizophrenia. Lancet 1981;1:666. 